\title{
Benchmarking of PR Function in Serbian Companies
}

Milan Nikolić, Zvonko Sajfert, Jelena Vukonjanski *

Abstract:

The purpose of this paper is to present methodologies for carrying out benchmarking of the PR function in Serbian companies and to test the practical application of the research results and proposed methods in real conditions. The paper begins with research on key PR function parameters in Serbian companies. Seventy PR managers were polled for this purpose. The data obtained were processed by applying factor analysis, after which five factors (parameters) which describe the attitudes of PR managers in Serbian companies were defined. Next a study was conducted of the defined parameters, or their situation, in the seven selected Serbian companies. Twenty-one managers were polled in the process providing the data for a mathematical function for comparison of the analyzed companies. The function is based on elements of quantitative and multi-criteria analysis. Among the main output data are: ranking of the analyzed benchmarking partners (aggregate and according to individual parameters), defining similarities between the partners, selection of the competent benchmarking partner, multicriteria selection of the best action and positioning the parameters of the selected action in the field of a particular portfolio matrix. It has been shown by concrete example that the proposed procedures have both theoretical and practical value. The presented procedures are not only limited to the PR process, but can also be applied to benchmarking other business processes.

Key words: PR function, benchmarking, survey, results, analyses, Serbia.

JEL: M19

DOI: $10.2478 / v 10033-009-0017-0$

\section{Introduction}

One of the most important segments of marketing is marketing communication. The aim of communication is to set the recipient of communication into action, which should be perceived more comprehensively in terms of creating a situation that could result in taking or giving up an action. Modern society has entered a new stage of development defined as the 'information society'. What is essential for doing business in the information society is the production and distribution of information. According to Kotler, Armstrong (1996), the fast development of information technologies and direct marketing has had the most important impact on forming a new pattern of marketing communication, which is defined as integrated marketing communication. This
*Milan Nikolić

Dept. of Management

University of Novi Sad, Serbia

Technical faculty “Mihajlo Pupin", Zrenjanin

\section{Zvonko Sajfert}

Dept. of Management

University of Novi Sad, Serbia

Technical faculty "Mihajlo Pupin", Zrenjanin

Jelena Vukonjanski,

Dept. of Management

University of Novi Sad, Serbia

Technical faculty "Mihajlo Pupin", Zrenjanin 
model involves careful integration and coordination of many communication channels - from the standard media of mass communication to direct marketing, which is designed to send a clear and consistent message about the company, its products and services.

A modern approach to a company's communicative activities implies integrating all the forms of communication aimed at achieving a synergic effect in the communication process. Along these lines, public relations assume the characteristics of a communicative activity that should permeate the entire process of market communication for a company. PR is a communication activity aimed at establishing and developing understanding with the general public which is itself divided into segments - and achieving public trust; that is, creating a favourable picture of the company.

According to Baskin, Aronoff and Lattimore (2000), PR can be observed and interpreted as a profession, process, communication with the general public and practice. In addition to this, PR represent a multidimensional and extremely complex business activity requiring knowledge of various fields of human activities (psychology, communication science, journalism, economics, politics, ethics, culture, etc.), and their integration in order to achieve efficient communication. Its objectives are to build good relationships with various segments of the general public on the grounds of publicity, to create a good corporate image and to solve problems generated by unfavourable stories, rumours and events. The importance of relations with the general public stems from the state of contemporary society, which is marked by the strong inter-dependence of all of its segments. A company is linked with other segments of society by multiple ties. Due to that fact, a company has to take care in forming and maintaining a mutual understanding with those segments that are of interest. The general public needs to become acquainted with all the activities of a company and this need grows with the strengthening of public opinion in modern society. In addition, a company has to pay due attention to building positive interpersonal relationships within the company itself (internal PR).

An important part of the communicative efforts of an organization is aimed at creating public opinion. Public opinion can be defined as the dominant attitude of the society, the collective will of the people, and the consensus opinion of the general public in relation to a particular issue. According to Black (2003), PR can be described with some key words: reputation, perception, credibility, trust, unity, mutual understanding, truthful and comprehensive disclosure. According to Wragg (1996), the main forms of PR include the following: relations with media, communication with employees, relations with investors, relations with politics, corporate identity, sponsorship, relations with the community, and relations with clients.

Brookes and Little, considering the appearance of organizations on the market in the future, define a new model of market activity designated as relationship marketing. This model is based on the following: database management, interactive market communication, and marketing networks (Brookes, Little, 1997). A new model of market management implies that the company has to meet the wider range of interests that dominate its social surroundings.

Relationship marketing is a significant paradigmatic breakthrough in approaches to marketing, from thinking only in categories of competition and conflict to thinking in categories of interdependence and collaboration. It recognizes the importance of different participants suppliers, employees, distributors, dealers, retail sellers, who collaborate in order to provide the target customer with the best value. The basic features of relationship marketing include (Kotler, 2004):

- orientation more toward partners and consumers than to products,

- greater stress laid on keeping and developing existing customers than on finding new customers,

- greater reliance on multifunctional teams than on work at the sector level,

- greater reliance on listening and learning than on talking.

By establishing an efficient PR function, the company has impact on forming, maintaining and developing the company's image in a positive direction. A favourable climate of public opinion, quality and differentiation of products are the prerequisites for a successful company image that will affect the overall business performance of the company.

\section{Public Relations in Serbia and in Other Countries}

Development of PR is particularly important in companies operating in countries in transition. Since PR involves communicative activities which have strategic importance for a company's business, it is usually positioned under executive management. In the process 
of transition, companies must have highly developed communicative activities with the segments of its surroundings, as well as with the internal public. These activities are even more manifest in companies which have completed the process of ownership transformation, especially in cases of direct foreign investments. With the completion of the process of economic transition, and with the coming of foreign capital on the market, PR plays an increasingly important part in the process of internalization of the process of doing business.

From the aspect of theory, the concept of PR has been present in Serbia since the mid-1980s. A more serious study of this discipline began at the beginning of the 1990s. It was at this time that PR practice in Serbian companies began.

At the beginning of the 1990s, PR appeared as an independent course of postgraduate study (Faculty of Economics in Belgrade, and Faculty of Organizational Sciences in Belgrade). In parallel with the studies of PR in specialist and master programs at the university level, studies within this area were also initiated in the field of informal educational systems where very important results were achieved. In the mid-1990s, several agencies - PR training centres - were founded (for example PRA Educa in Belgrade, etc.). It is interesting that the largest number of individuals who deal with PR in practice have completed instructional seminars with one of the organizations which were dealing with training in the field of PR. The lectures at these seminars were mostly given by practitioners from various fields which partly deal with PR, such as journalists, communication experts, marketing experts, advertising experts, etc.

As a specific form of marketing communication, PR had a minor role in the overall communication process of Serbian companies on the domestic market. Nor was PR well-established when Serbian companies appeared on foreign markets. PR activity was not well-established in a large number of Serbian companies during the 1990s. In the late 1990s, with the establishment of a larger number of foreign marketing agencies, a more significant presence of this activity emerged in the practices of companies which operate on the Serbian market. However, PR, as a business activity, is still only beginning to establish itself on the Serbian market. The development of a market economy and the acceptance of private capital logically contribute to acknowledgment of the fact that this activity is very necessary.
According to Taylor (2004), a similar situation (but somehow more favourable) is present in referent neighbouring countries (Croatia, Bosnia and Herzegovina, Hungary, Romania, Bulgaria). In these countries, PR activity has been developing more intensively over the past 15 years. In Serbia, such trends started later, and more intensively only after 2000 . Over the last few years, the public relations practice has made substantial progress because of the increased number of foreign and international companies which have entered the Serbian market. All this created the need to examine and study $\mathrm{PR}$, as well as the very people who deal with this activity.

Gill et al. (2008) compared various companies from North America, Europe and Asia according to three types of indicators linked with communication. North American companies pay most attention to environmental and economic indicators, while companies from Europe give advantage to social indicators.

According to Sterne (2008), there is a relatively negative opinion about PR managers in New Zeland. There is a clear difference between PR consultants from other companies and PR within the company itself. It is better when PR is an integral part of the company, especially during a crisis. This research has showed that marketing "sees" PR as its own service, while top management "sees" PR as a service of the company's strategic objectives.

In Belgium, realization of PR activities and communication is too focused on positive aspects (Gelders, 2007). Quality and quantity of communication in Belgian companies are not on a high level. The use of additional media has been suggested.

According to Leonard and Grobler (2006), in South America more attention is paid to external than to internal communication, because external communication is considered to have greater strategic significance. Many PR managers think that communication presents tactical tools without strategic significance. Therefore, PR managers are not appreciated adequately. It has been found that in South Africa there exists a need for a new type of PR manager who will be able to deal with its complex business atmosphere. Similarly, other research (Niemann-Struweg and Meintjes, 2008) has pointed out problems facing PR managers in South Africa and the need for professionalization of this activity, as well as the need for improving the influence of the PR profession in South Africa.

Koc (2006) studied the ethics of communication in written media in Turkey. This research showed that PR 
managers in Turkey mostly had a teleological point of view.

Kirat (2006) studied the development of PR in the United Arab Emirates. In this country the PR profession is under the great influence of social, economic, educational and cultural development. It is obvious that the need for PR managers is increasing and the perspectives of the profession are very good.

Kent et al. (2006) studied the development of PR in Bosnia and Hercegovina. Generally speaking, it was established that PR had the potential to improve business in Bosnia and Hercegovina. PR managers are good at their jobs, but there are limits placed on their work by transitional business conditions.

According to research carried out in Croatia (Žlof, 2007), journalists think that PR in Croatia has been developed and is constantly on the rise. The journalists are critical when issues of the education and professionalism of PR managers are in question. It is interesting that, like in New Zeland, PR managers from within the companies themselves are trusted more than those from specialised consulting agencies.

Based on everything said, it can be concluded that PR in many countries of the world are still in progress. However, there is strong potential in the PR profession, as well as a tendency for the improvement of its importance and reputation. Serbia is not an exception, which has been proven by research (Nikolić, Đorđević, Coćkalo, 2007), and by the results of factor analyses presented in section 5.2 of this paper.

\section{Benchmarking and its Application in Serbian Companies}

The present-day situation on the world market is characterized by the presence of very strong competition, and numerous and fast changes in its settings. In the new millennium, one fact is crystal clear - only those companies which have accustomed themselves to changing and adapting quickly, which means learning fast, will succeed.

Modern management has developed numerous techniques for achieving better business results in order to live with these changes. This is how techniques such as Canban, Just in Time, Re-Engineering, TQM, and others were originally developed. During the 1980s, managerial techniques were completed with benchmarking, which is now a widely acknowledged and verified tool of modern management. This technique implies that the objectives and methods of their accomplishment are defined by following the practices of the best companies worldwide. Benchmarking, as a part of strategic management, offers a company guidelines for enhancing its business processes, technical solutions and functions.

The term 'benchmarking' has been reported and defined in widely different ways. For instance, Venetucci (1992) defined benchmarking as a process of gathering standards for improvement and insights which may lead the organization to better performance. McNair and Leibfried (1992) described benchmarking as an external focus on internal activities in order to obtain continuous improvement. According to Camp (1995), benchmarking is a continuous process of evaluation of production process, products, and services with reference to those of the strongest competitors, known as best practice.

There are a significant number of different approaches to the methods of organizing, i.e., carrying out benchmarking research. Most of these researches have in common certain parameters (relevant for the observed process) that are specifically quantified, and then compared with best practice. The data are usually compiled through surveys, and are then statistically processed and compared. A similar approach is present in many references, including, for example Alshawaf et al. (2005); Bouchereau and Rowlands (2000); Garg and Ma,(2005); Koh et al. (2005); Ungan (2004).

Performance measurement and benchmarking are the main techniques that have been used by many leading researchers on improving company performance (Camp, 1989; Gunasekaran et al., 2001; Zairi, 1998). Neely (1998) suggested that measuring the performance of companies would enable areas of improvement to be prioritized and actions to be taken.

However, despite its great potential, the quantitative approach is still insufficiently present in benchmarking. This particularly refers to the application of benchmarking in real-life conditions in Serbia (and the majority of countries in transition). Benchmarking is very rarely practiced in Serbian companies. Among other things, problems arise because of the lack of a concrete, practical, simple, and defined quantitative method which would enable obtaining applicable and useful results. This method is to a considerable extent adapted to the conditions in the Serbian economy, and would represent encouragement and incentive for the wider application of benchmarking.

Nikolić, Nikolić and Vukonjaski (2007) offer some suggestions on how to use the quantitative approach 
when comparing a company with its competitors, selecting a competent benchmarking partner and choosing the optimal strategic action. These proposals were inspired by numerous references which elaborate and apply various methods of quantitative and multicriteria analyses (Brans et al., 1984; Hwang and Yoon, 1981; McCrimmon, 1968; Oberstone, 1990; Srinivasan and Shoker, 1973).

Nikolić, Nikolić and Vukonjaski (2007) also present a two-criteria selection of the benchmarking partner, which is based on the partner's quality, and on the possibilities of the company which performs benchmarking. This procedure originated as a reply to the current situation in Serbia. In other words, benchmarking is still not studied and accepted in the Serbian economy. Most companies in Serbia hardly apply this technique at all, or if they do, they do it in some sort of improvised form. The reasons for this situation (together with the above-mentioned) can be found in considerable technological underdevelopment and very poor financial potential. Despite all of this, there is a rising awareness that the application of quality and systematic benchmarking is a necessary prerequisite for the development and survival of Serbian companies on the increasingly demanding international market. There is also a view that Serbian companies ought not to aim at maximizing their performance by following the 'Best in Practice' model. The highest aspirations are still unachievable, which does not mean that benchmarking should be given up. On the contrary, its application should be intensified, but with somewhat more modest objectives. Once these objectives have been achieved, it is possible to aim at achieving a higher level. Such an approach could be characterized as setting targets in steps, which is one of the possibilities set out in Walsh (2000).

\section{Research Methodology}

The objective of the paper is to correlate the problem area of PR management and the problem area of benchmarking. It was performed by carrying out PR function benchmarking on a concrete example in seven Serbian companies. In order to render this possible, two independent studies were carried out beforehand.

1. Research on the particular aspects of PR functions in Serbian companies (Study 1). The integral results of this study are presented in Nikolić, Djordjević and Coćokalo (2007). Of most relevance to the purpose of this paper is the section dealing with the identification of the factors which describe (present) the attitudes of PR managers in Serbia. This part is presented in section 5 of this paper.

2. Research on the possibilities of applying the quantitative approach in benchmarking (Study 2). The integral results of this study are presented in Nikolić, Nikolić and Vukonjanski (2007). These results are not specifically presented in this paper, but are applied directly to the example here.

The results of the two above-mentioned studies are integrated into this paper. Benchmarking of the PR function is essentially carried out according to the identified factors (Study 1) by applying a mathematical function (Study 2). In this way, both studies have achieved their practical applications.

This paper deals with seven benchmarking partners (BP). For each BP identification factors are marked by a mark from the interval $[0,1]$, according to the factor condition in relation to the studied BP. Comparison of BP is performed according to the marks which are given to all factors. The significance difficulties of factors are taken into account. They are also obtained from the results of factor analyses. After evaluation of all BP according to the factors and by application of appropriate mathematical procedures (presented in section 6 of this paper), it is possible to carry out:

- determination of partial and total differences between a determined and other BP

- determination of similarities among BP

- two-criteria selection of competent BP

- selection of optimal strategic activity

The methodology described can be applied to various numbers of BP and identified factors, as well as to different business processes. The selection of factors and determination of their difficulties can be carried out by other procedures and not only by factor analyses.

A similar way of collecting data and processing by factor analyses was used in Eid et al. (2006), for research and identification of critical factors of success in business - to - business international internet marketing. Ribeiro and Cabral (2006) developed a special benchmarking model for evaluation of performances based on critical factors. Finally, Moffet et al. (2008) emphasize the importance of measuring performances in benchmarking. 


\section{Identification of the Factors which Describe the Attitudes of PR Managers in Serbia}

\subsection{Characteristics of Study 1}

Study 1 was carried out by polling experts (PR managers) who are employed in companies operating in different fields of business activities. The basic characteristics of the process and the results of polling are the following:

- The number of $P R$ managers. A total of $\mathbf{N}=\mathbf{7 0}$ managers from 70 different companies were polled and gave their answers. It is estimated that this number represents one third of all PR managers in Serbia. The relatively small number of PR managers stems from the fact that many companies do not have an independent PR function and employees who would deal exclusively with PR. In many companies, the PR function is a part of other functions, usually marketing. Also, very frequently, there are no persons specialized for this job since it is considered unnecessary for good business results.

- Research area in geographical terms. The research was carried out within the territory of Serbia.

- Time period of the research. The research lasted six months, approximately the period between March 1 and September 1, 2006.

- Types of questions. The survey consisted of 29 questions which were subdivided into three groups: a) questions on the positions of PR managers and their profession, b) questions on the characteristics and education of PR managers, and c) questions on the most frequent and most important activities and media for the realization of the PR function.

- Question formulating. The questions were formulated so as to encompass all the topics of interest for this study. Various studies which cover these topics were used, including: PR manager career development (Wolf, 2006), PR manager satisfaction (Abbott, 2003), and PR manager education and skills (Elliot, Koper, 2003; Lubbers, 2002; Murray, 2003; Rawel, 2003). Studies which examine other countries' experience in the field of PR (Arceo, 2004; Bardhan, Sriramesh 2006; Guth, 2000; Raupp, Ruler, 2006; Taylor, 2004) had an important impact on creating and completing the questionnaire, as well as the references by the authors who deal with PR in the conditions of the study's subject matter (Djordjević, Ćoćkalo, 2004; Djordjević, Bešić, 2004; Filipović,
Kostić, Prohaska, 2003; Sajfert, Djordjević, Bešić, 2006).

\subsection{Key attitude dimensions of PR managers in Serbia}

Part of the input data (14 questions) has been processed by factor analysis. Principal Component Analysis (PCA) has also been applied. The selection of the number of factors has been made according to the Kaiser - Guttman criterion. Five factors have been identified which refer to the PR function in Serbian companies (Table 1). These factors cover around $67 \%$ of variations in the attitudes of PR managers in Serbia.

\begin{tabular}{|c|c|c|c|c|}
\hline Factor & Eigenvalue & $\begin{array}{c}\text { Total } \\
\text { Variance } \%\end{array}$ & $\begin{array}{c}\text { Cumulative } \\
\text { Eigenvalue }\end{array}$ & $\begin{array}{c}\text { Cumulative } \\
\%\end{array}$ \\
\hline 1 & 4.207772 & 30.05551 & 4.207772 & 30.05551 \\
\hline 2 & 1.487835 & 10.62739 & 5.695606 & 40.68290 \\
\hline 3 & 1.341726 & 9.58376 & 7.037332 & 50.26666 \\
\hline 4 & 1.220627 & 8.71876 & 8.257959 & 58.98542 \\
\hline 5 & 1.092717 & 7.80512 & 9.350677 & 66.79055 \\
\hline
\end{tabular}

Table 1: PR function factors in Serbian companies (Eigenvalues and percent of variance explained)

The identified factors have been rotated by applying the varimax method. The results of the rotation are shown in Table 2. (Table 2 shows the questions which have been processed by factor analysis).

The identified factors have been interpreted on the basis of the results shown in Table 5. In this way, the factors which describe (represent) the attitudes of PR managers in Serbia have been defined: (Nikolić, Djordjević, Ćoćkalo, 2007)

F1 - Satisfaction with PR function, subjective and

organizational

F2 - PR managers' personal prospects

F3 - PR managers' personal reputation

F4 - Quality of professional improvement of PR managers F5 - PR managers' previous education

Interpretation of the factors points to the fact that PR managers in Serbia are ambitious, proactive people to whom non-material categories are more important than material ones, including: reputation and success of PR function in the company, satisfaction and prospects in the job, personal reputation and professional improvement. These results can be considered encouraging, both in terms of the prospects of PR management in Serbia and 
Benchmarking of PR Function in Serbian Companies

\begin{tabular}{|c|c|c|c|c|c|}
\hline Variable & Factor 1 & Factor 2 & Factor 3 & Factor 4 & Factor 5 \\
\hline 1. How satisfied are you with the job of PR manager? & 0.684372 & 0.213864 & 0.257448 & 0.133309 & 0.335958 \\
\hline 2. How motivated are you for the job of PR manager? & 0.558219 & 0.116729 & 0.178601 & -0.334462 & 0.392191 \\
\hline $\begin{array}{l}\text { 3. What are the chances of professional improvement from } \\
\text { the position of PR manager? }\end{array}$ & -0.012954 & 0.788356 & 0.072369 & 0.005396 & 0.127302 \\
\hline $\begin{array}{l}\text { 4. What are the chances of career promotion from the } \\
\text { position of PR manager? }\end{array}$ & -0.003215 & 0.519737 & 0.646401 & -0.154804 & -0.017002 \\
\hline $\begin{array}{l}\text { 5. How important do you think your job is for the } \\
\text { company's business success? }\end{array}$ & 0.060712 & -0.031999 & 0.762151 & 0.146025 & 0.366193 \\
\hline $\begin{array}{l}\text { 6. How appreciated is the job of PR manager in your } \\
\text { company? }\end{array}$ & 0.735325 & 0.027169 & 0.231686 & 0.094560 & -0.260227 \\
\hline $\begin{array}{l}\text { 7. How much is the work in PR management appreciated } \\
\text { by your friends? }\end{array}$ & 0.278456 & 0.074140 & 0.724708 & 0.203316 & -0.119266 \\
\hline $\begin{array}{l}\text { 8. How appropriate is the work in PR management in } \\
\text { Serbia? }\end{array}$ & 0.497272 & 0.624425 & -0.116968 & 0.283397 & -0.141129 \\
\hline 9. What are the prospects of your profession in Serbia? & 0.136814 & 0.627678 & 0.143179 & 0.600315 & 0.065166 \\
\hline $\begin{array}{l}\text { 10. How much does your education help you in the job of } \\
\text { PR manager? }\end{array}$ & 0.038716 & 0.112226 & 0.038823 & 0.217611 & 0.834682 \\
\hline $\begin{array}{l}\text { 11. What is the need for developing specialized educational } \\
\text { programmes for acquiring knowledge and skills in the field } \\
\text { of PR? }\end{array}$ & 0.112110 & 0.003993 & 0.173003 & 0.814331 & 0.161748 \\
\hline 12. How much do you enjoy working with people? & 0.189002 & 0.492515 & 0.116433 & -0.097955 & 0.402627 \\
\hline 13. How successful do you think you are in your job? & 0.594533 & -0.002989 & 0.431403 & 0.297490 & 0.073827 \\
\hline 14. How successful do you think is PR in your company? & 0.652442 & 0.066648 & -0.081882 & 0.023801 & 0.100121 \\
\hline Expl. Var. & 2.497016 & 2.001773 & 1.952991 & 1.475076 & 1.423820 \\
\hline Prp. Totl & 0.178358 & 0.142984 & 0.139499 & 0.105363 & 0.101701 \\
\hline
\end{tabular}

Table 2: Factor loadings (varimax normalized rotation); Extraction: Principal components

in terms of creating and developing a positive climate and high system of values in Serbian companies.

\section{Benchmarking of PR Function According to the Defined Factors}

In this section, the application of the results of Study 1 and Study 2 is given through a concrete example. To render this possible, it was necessary to carry out Study 3 (which was carried out for the needs of this paper).

\subsection{Characteristics of Study 3}

Study 3 is essentially aimed at gathering the data on the defined factors for each analyzed company (the companies on which benchmarking is performed - seven companies). After this, benchmarking of the PR function in the analyzed companies is carried out on the basis of these data (the input) by applying a mathematical function (Study 2).

Study 3 was carried out by polling the experts (PR managers) who are employed in the analyzed companies. The basic characteristics of the polling process and the results are the following:

- The number of PR managers. Answers by the total of $\mathbf{n}$ = 21 polled $P R$ managers from seven analyzed companies were received (three PR managers from each company). 


\begin{tabular}{|c|c|c|c|c|c|c|c|c|}
\hline \multirow{2}{*}{$\begin{array}{l}\text { Parameter of PR function } \\
\text { in Serbian companies } X_{i}\end{array}$} & \multirow{2}{*}{$\begin{array}{c}\text { Relative } \\
\text { parameter } \\
\text { weights } \mathrm{W}_{\mathrm{i}}\end{array}$} & \multicolumn{7}{|c|}{ Assessments of the all benchmarking partners $\mathrm{BP}_{j}$} \\
\hline & & $\mathrm{BP}_{1}$ & $\mathrm{BP}_{2}$ & $\mathrm{BP}_{3}$ & $\mathrm{BP}_{4}$ & $\mathrm{BP}_{5}$ & $\mathrm{BP}_{6}$ & $\mathrm{BP}_{7}$ \\
\hline $\mathrm{X}_{1}-\mathrm{F} 1$ & 0.4500 & 0.448 & 0.762 & 0.838 & 0.452 & 0.690 & 0.533 & 0.667 \\
\hline $\mathrm{X}_{2}-\mathrm{F} 2$ & 0.1591 & 0.495 & 0.876 & 0.852 & 0.471 & 0.767 & 0.567 & 0.771 \\
\hline $\mathrm{X}_{3}-\mathrm{F} 3$ & 0.1435 & 0.657 & 0.857 & 0.957 & 0.381 & 0.829 & 0.438 & 0.633 \\
\hline$X_{4}-F 4$ & 0.1305 & 0.609 & 0.938 & 0.948 & 0.367 & 0.714 & 0.724 & 0.652 \\
\hline$X_{5}-F 5$ & 0.1169 & 0.652 & 0.776 & 0.867 & 0.580 & 0.724 & 0.557 & 0.833 \\
\hline \multicolumn{2}{|c|}{ Aggregate assessments $S A_{j}$} & 0.530 & 0.818 & 0.875 & 0.449 & 0.729 & 0.552 & 0.696 \\
\hline \multicolumn{2}{|l|}{ Rank } & 6 & 2 & 1 & 7 & 3 & 5 & 4 \\
\hline
\end{tabular}

Table 3: Initial table with the given assessments

- Research area in geographical terms. The research was carried out on the territory of Serbia (all the seven analyzed companies are from Serbia).

- Research time. The research lasted approximately two months, from May 1 to July 1, 2008.

- Type of questions. The survey consisted of five questions which, in fact, represent the defined factors from Study 1.

- Assessment method. PR managers assessed, according to their opinion, the situation of the defined factors by awarding an assessment from the $[0,1]$ interval. In the process, they used the interval scale divided into five levels: a very low level (assessement in the range between $0-0.2$, with the interval median at 0.1 ), a low level (assessement in the range between 0.2-0.4, with the interval median at 0.3), an average level (assessement in the range between 0.4-0.6, with the interval median at 0.5) a high level (assessment in the range between 0.6-0.8, with the interval median at 0.7 ), and a very high level (assessment in the range between 0.8-1, with the interval median at 0.9).

- Assessment procedure. Each PR manager assessed the situation of each factor in his/her compnay and in the other six companies. In this way, each factor was assessed 21 times. This type of procedure carries with it the danger of manifesting subjectivity when assessing other companies. However, in this way the possibility of the respondents' using different parts of the $[0,1]$ interval is avoided. In addition, the PR managers in this way directly correlated all of the analyzed companies.

\subsection{Formation of the initial table}

The results of Research 3 enabled formation of the initial table (Table 3 ), which should contain the following data:

- Parameter list - company characteristics $\left(X_{i}\right)$ according to which benchmarking is to be carried out (first column in Table 3). The parameters shown here are, in fact, the factors which were defined in Research 1.

- Parameter relative weights $\left(w_{i}\right)$, with which the importance of individual parametres is taken into account (second column in Table 3). Relative weights can be determined either according to the estimate of the managers in the company carrying out benchmarking or on the basis of surveying the experts on the importance of the analyzed parametres. Determining relative weights (criteria or parameters) is a significant problem which was frequently dealt with in multicriteria analysis literature, for example in (Leskinen, 2000; Noghin, 1997; Podinovski, 2002). In this case, the results of factor analysis from Research 1 were used for determining the parameter relative values. The relative weights were in this way determined as normalized values of the second column in Table 1.

- Characteristics of all of the seven analyzed companies - benchmarking partners $\left(\mathrm{BP}_{\mathrm{j}}\right)$ are expressed by assessments $[0,1]$ for each analyzed (ith) parameter (other columns in Table 3). These are the assessments obtained as average values of the assessments which were given by PR managers within the framework of Study 3. Each assessment was obtained as the average of 21 assessments given by 21 polled PR managers. 
Table 3 shows aggregate assessments of each $\mathrm{BP}_{\mathrm{j}}$. Aggregate assessments are calculated through the following formula:

$$
\mathrm{SA}_{\mathrm{j}}=\sum_{\mathrm{i}=1}^{\mathrm{n}} \mathrm{V}_{\mathrm{ij}} \cdot \mathrm{W}_{\mathrm{i}},
$$

in which:

$S A_{j}$ - is the aggregate assessment for the $j$-th company, where: $j=1,2, \ldots$, $s$, and $s$ - the number of the analyzed companies,

$\mathrm{V}_{\mathrm{ij}}$ - assessment of the $\mathrm{i}$-th parameter for the $\mathrm{j}$-th company, where $\mathrm{i}=1$, $2, \ldots, n$, and $n$ - the number of parameters,

$\mathrm{W}_{\mathrm{i}}$ - relative weight of the $\mathrm{i}$-th parameter.

For example, for $\mathrm{BP}_{1}$, the aggregate assessment is calculated in the following way:

$\mathrm{SA}_{1}=0.448 \cdot 0.4500+0.495 \cdot 0.1591+0.657 \cdot 0.1435+$ $0.609 \cdot 0.1305+0.652 \cdot 0.1169=0.530$

The aggregate assessments calculated in this way are in fact OWA aggregation operators (Yager, 1988).

Table 3 provides the following information:

1. It can be seen which benchmarking partner is the best and which is the weakest for each parameter separately.

2. Aggregate assessments for each benchmarking partner can be seen as well as their position in relation to other BPs.

3. The ranks of all of the analyzed companies can be seen for all of the analyzed companies, according to the aggregate assessments.

\subsection{Determining partial and overall differences}

The data given in Table 3 enable carrying out the next step, which is determining the partial and overall differences between a definite BP and other BPs. In further analyses, $\mathrm{BP}_{1}$ is observed as the company ranking $6^{\text {th }}$ in Table 3. This company was selected as the subject of further research. In this way, the research results are practically tested for the company which has real needs for benchmarking. $\mathrm{BP}_{1}$ is hereafter called a 'concrete company' - CC. Partial and overall differences between the $\mathrm{CC}\left(\mathrm{BP}_{1}\right)$ and other BPs are given in Table 4.

The central part of Table 4 consists of the relative distances of the CC for each parameter in relation to each BP. The "-" sign shows that CC is falling behind in relation to the observed BP and, vice versa, the " + " sign shows that the CC is leading the way in relation to the observed $\mathrm{BP}$. The relative distance is determined through the following formula:

$d_{i j}=\left(V_{i, c c}-V_{i j}\right) \cdot w_{i}$,

in which:

$\mathrm{d}_{\mathrm{ij}}$ - is the relative distance between the CC and the $\mathrm{j}$-th BP for the $\mathrm{i}$-th parameter, where: $\mathrm{i}=1,2, \ldots, \mathrm{n}$, and $\mathrm{n}$ - is the number of parameters $\mathrm{j}=$ $2, \ldots, \mathrm{s}$,

$\mathrm{V}_{\mathrm{i}, \mathrm{CC}}$ - the assessment of the $\mathrm{i}$-th parameter for the CC,

$V_{i j}$ - the assessment of the $i$-th parameter for the j-th BP.

The relative distances in Table 4 have been calculated by Formula (2). For example, according to the parameter $\mathrm{X}_{1}-\mathrm{F} 1$, the relative distance between the $\mathrm{CC}$ and $\mathrm{BP}_{2}$ is:

$d_{12}=(0.448-0.762) \cdot 0.4500=-0.141$

Table 4 provides the following information:

1. It can be seen in which parameter the CC is falling behind most and which the least in relation to a BP.

2. If one single parameter is observed separately, its position in relation to all of the BP's can be seen. In other words, it can be seen which parameter is falling behind most or least or is leading the way in relation to which BP.

3. In the last column can be seen the aggregate situation of certain parameters in relation to all of the BPs. These values are obtained by adding up the relative distances of all the rows.

\begin{tabular}{|c|c|c|c|c|c|c|c|c|c|}
\hline \multirow{2}{*}{$X_{i}$} & \multirow{2}{*}{$W_{i}$} & \multirow{2}{*}{$\mathrm{CC}\left(\mathrm{BP}_{1}\right)$} & \multicolumn{6}{|c|}{ Relative distance $\mathrm{CC}$ in relation to $\mathrm{BP}_{\mathrm{j}}$} & \multirow{2}{*}{$\begin{array}{c}\text { Aggregate } \\
\text { position of some } \\
\text { parameters }\end{array}$} \\
\hline & & & $\mathrm{BP}_{2}$ & $\mathrm{BP}_{3}$ & $\mathrm{BP}_{4}$ & $\mathrm{BP}_{5}$ & $\mathrm{BP}_{6}$ & $\mathrm{BP}_{7}$ & \\
\hline$X_{1}-F 1$ & 0.4500 & 0.448 & -0.141 & -0.176 & -0.002 & -0.109 & -0.038 & -0.098 & -0.564 \\
\hline$X_{2}-F 2$ & 0.1591 & 0.495 & -0.061 & -0.057 & +0.004 & -0.043 & -0.011 & -0.044 & -0.212 \\
\hline$X_{3}-F 3$ & 0.1435 & 0.657 & -0.029 & -0.043 & +0.040 & -0.025 & +0.031 & +0.003 & -0.023 \\
\hline$X_{4}-F 4$ & 0.1305 & 0.609 & -0.043 & -0.044 & +0.032 & -0.014 & -0.015 & -0.006 & -0.090 \\
\hline$X_{5}-F 5$ & 0.1169 & 0.652 & -0.014 & -0.025 & +0.008 & -0.008 & +0.011 & -0.021 & -0.049 \\
\hline \multicolumn{3}{|c|}{ Position of $\mathrm{CC}$ in relation to $\mathrm{BP}_{\mathrm{j}}$} & -0.288 & -0.345 & +0.082 & -0.199 & -0.022 & -0.166 & \\
\hline
\end{tabular}

Table 4: Determining partial and overall differences 


\begin{tabular}{|c|c|c|c|c|c|c|c|c|c|}
\hline & $\mathrm{CC}\left(\mathrm{BP}_{1}\right)$ & $\mathrm{BP}_{2}$ & $\mathrm{BP}_{3}$ & $\mathrm{BP}_{4}$ & $\mathrm{BP}_{5}$ & $\mathrm{BP}_{6}$ & $\mathrm{BP}_{7}$ & $m_{a v, j}$ & \\
\hline $\mathrm{CC}\left(\mathrm{BP}_{1}\right)$ & - & 0.712 & 0.655 & 0.914 & 0.801 & 0.894 & 0.828 & 0.801 & \\
\hline $\mathrm{BP}_{2}$ & 0.712 & - & 0.936 & 0.630 & 0.911 & 0.734 & 0.864 & 0.798 & \\
\hline $\mathrm{BP}_{3}$ & 0.655 & 0.936 & - & 0.574 & 0.854 & 0.677 & 0.821 & 0.753 & \\
\hline $\mathrm{BP}_{4}$ & 0.914 & 0.630 & 0.574 & - & 0.719 & 0.891 & 0.753 & 0.747 & \\
\hline $\mathrm{BP}_{5}$ & 0.801 & 0.911 & 0.854 & 0.719 & - & 0.821 & 0.940 & 0.841 & $\mathrm{~m}_{\mathrm{av}, \max }$ \\
\hline $\mathrm{BP}_{6}$ & 0.894 & 0.734 & 0.677 & 0.891 & 0.821 & - & 0.838 & 0.809 & \\
\hline $\mathrm{BP}_{7}$ & 0.828 & 0.864 & 0.821 & 0.753 & 0.940 & 0.838 & - & 0.841 & $\mathrm{~m}_{\mathrm{av}, \max }$ \\
\hline
\end{tabular}

Table 5: Similarities of the analyzed companies

4. In the last row can be seen the aggregate position of the CC to all BPs. These values are obtained by adding up the relative distances in each column. They can be also obtained as the difference of the aggregate assessment $\mathrm{CC}\left(\mathrm{BP}_{1}\right)$ and aggregate assessments of other BPs (Table 3 ).

\subsection{Determining mutual similarities}

Previous calculations enable one more type of analysis, which is determining the similarities of the $C C$ to each BP, as well as the similarities between all the BPs. Table 5 is formed on the basis of the data given in Table 3, and it shows all the mutual similarity measures for the seven analyzed companies.

Similarity measures are determined through the corresponding expression - measure. The right selection of the measure poses a particular problem. References which treat the area of multicriteria decision-making and fuzzy sets (Höppner et al., 1999; Farinwata et al., 2000; Klement et al., 2004; Pedrycz, Gomide, 1998; Royo, Verdegay, 2000) were particularly helpful in the process. On the basis of this, as well as on the basis of the needs and specificities of the given problem area, a measure based on Hamming's distance was defined:

$\mathrm{m}_{\mathrm{ab}}=1-\sum_{\mathrm{i}=1}^{\mathrm{n}}\left|\mathrm{V}_{\mathrm{ia}}-\mathrm{V}_{\mathrm{ib}}\right| \cdot \mathrm{w}_{\mathrm{i}}$,

in which:

$m_{a b}$ - measure of similarity of the a-th company to the b-th company,

$V_{i a}$-assessment of the $i$-th parameter for the a-th company,

$V_{i b}$ - assessment of the $i$-th parameter for the $b$-th company,

$n$ - the number of parameters.

The subtrahend in the Expression (3) actually represents the relative difference (distance) between the a-th and the b-th companies. The measure of similarity takes the value from the $[0,1]$ interval. The equivalence $m_{a b}=m_{b a}$, holds true in the process, which can also be seen in Table 5. Since the companies are not compared to themselves, the diagonal fields in Table 5 are blank.

All the measures of similarity in Table 5 have been calculated through the defined measure - expression (3). For example, the measure of similarity for $\mathrm{CC}$ and $\mathrm{BP}_{2}$ is:

$\mathrm{m}_{\mathrm{Cc}, 2}=1-[|0.448-0.762| \cdot 0.4500+|0.495-0.876|$. $0.1591+|0.657-0.857| \cdot 0.1435+$

$$
+|0.609-0.938| \cdot 0.1305+|0.652-0.776| \text {. }
$$

$0.1169]=0.712$

The last column in Table 5 shows the average similarity measures $\left(m_{a v, j}\right)$ of one company in relation to the others. They are calculated in the following way:

$$
\mathrm{m}_{\mathrm{av}, \mathrm{j}}=\frac{\sum_{\substack{\mathrm{i}=1 \\ \mathrm{i} \neq \mathrm{j}}}^{\mathrm{s}} \mathrm{m}_{\mathrm{ij}}}{\mathrm{s}-1} .
$$

For example, for the $\mathrm{CC}$, the average similarity measure is: $\mathrm{m}_{\mathrm{av}, \mathrm{CC}}=(0.712+0.655+0.914+0.801+0.894+0.828):(7$ $-1)=0.801$.

Table 5 provides the following information:

1. Observation of individual measures of similarity of the CC to each BP, as well as the measures of similarity between all the BPs. In this way, it can be seen which BP the CC is most similar to according to the observed parameter. It can also be seen to which BP the CC has the least similarity. This information should be taken carefully, since great similarity to (or difference from) a BP does not mean that one should aim at its characteristics. This information only has to additionally facilitate a better view of the existing situation and easier comparison with a BP. Table 4 shows that the $C C$ is closest to $\mathrm{BP}_{6}$ by its aggregate assessment (the situation of $C C$ in relation to $\mathrm{BP}_{6}$ is expressed with the minimum absolute value 0.022 in the last row of Table 4). Table 5 shows that the CC is most similar to $\mathrm{BP}_{4}$ (the position of $\mathrm{CC}$ in relation to $\mathrm{BP}_{4}$ is expressed by the maximum similarity measure in the second column of Table 5). 
2. Observing the companies with the maximum average similarity measure (in the example given, these are $\mathrm{BP}_{5}$ and $\mathrm{BP}_{7}$ ). These companies are closest to the average, and other companies can also be positioned in relation to them in this way.

\subsection{Selection of the competent benchmarking partner}

What is here understood as the 'competent benchmarking partner' is the company in relation to which the CC will set its objectives and undertake strategic actions in order to achieve the desired (required) level of PR function. The selection of the competent BP is a very important step in every benchmarking process. Much attention has been dedicated to this problem area in the literature, for example Razmi, et al. (2000) and Lau, et al. (2001). In general, it is aimed at selecting the BP which has the best characteristics and business results. According to the analyses carried out in Tables 3, 4, and 5, it is obvious that in the observed example, $\mathrm{BP}_{3}$ has the best practice. A general recommendation for the CC would be that it should carry out its business processes by following the example of $\mathrm{BP}_{3}$.

As was mentioned in the introduction, the conditions of transition in Serbia impose the need for a different approach to the selection of a competent benchmarking partner. In other words, companies in Serbia are in most cases unable to aim at the best practice. For this reason they have to opt for the BP which has somewhat more modest, but still achievable business results. Unachievable business results are those which primarily require the application of cutting edge technologies, and generally larger financial investments. The companies operating in Serbia (and in countries with a similar level of economic development) are suggested to select from the competent BP on the basis of two criteria: $C_{1}$ - Quality and Business Results, and $C_{2}$ - Reality of Attainment of the Set Objectives (the amount of the required financial investments). Criteria $C_{1}$ and $C_{2}$ can be divided into subcriteria. For criterion $C_{1}$, the subcriteria could be: $C_{11}$ BP's Effects and Results, $\mathrm{C}_{12}$ - BP's Status and Reputation, $C_{13}$ - BP's Perspectives, $C_{14}$ - BP's Popularity with Consumers, $C_{15}$ - BP's Presence in the Media, etc. For criterion $C_{2}$, the subcriteria could be: $C_{21}$ - Harmonization with Business Policy; $C_{22}$ - Possession of Spatial Capacities, $C_{23}$ - Possession of Technology, $C_{24}$ - Possession of Machinery and Equipment, $C_{25}$ - Possibility of Supply of
Raw Materials, $C_{26}$ - Ability of Human Resources, $C_{27}$ Restitution Time of Investments, etc.

CC selects the criteria and the subcriteria for selecting the competent BPs in accordance with their possibilities and experience. The same goes for determining the relative weights of the criteria and subcriteria. A further procedure of applying the selected set of criteria and subcriteria can be realized in more ways. What follows is the applied procedure (simple, without subcriteria).

The two-criteria selection of the competent BP proposed here is to be carried out in the following way: the aggregate, two-criteria assessment of each BP is looked for, and the BP which has the highest assessment is adopted. The aggregate, two-criteria assessment for $\mathrm{BPi}$ is determined with the expression:

$\mathrm{TCA}_{\mathrm{j}}=\mathrm{A}_{\mathrm{C} 1 \mathrm{j}} \cdot \mathrm{W}_{\mathrm{C} 1}+\mathrm{A}_{\mathrm{C} 2 \mathrm{j}} \cdot \mathrm{W}_{\mathrm{C} 2}$

in which:

$T C A_{j}$ - the aggregate, two-criteria assessment of the j-th BP,

$A_{c 1 j}$ - the assessment of the $j$-th $B P$ according to the criterion $C_{1}$,

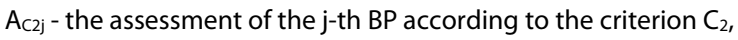

$\mathrm{W}_{\mathrm{C}_{1} 1}$ - the relative weight of the criterion $\mathrm{C}_{1}$,

$\mathrm{W}_{\mathrm{C} 2}$ - the relative weight of the criterion $\mathrm{C}_{2}$.

The aggregate assessment $S A_{j}$ of the j-th $\mathrm{BP}$ can be taken as the $A_{c_{1 j}}$ assessment. The percentage of achievement of the analyzed parameters can be taken as the $A_{c 2 j}$ assessment, or the percental measure in which the CC already possesses the level of the particular BPs. Therefore, the $A_{c 2 j}$ assessment is determined as the relation of the aggregate assessment of the $C C$ and the aggregate assessment of the $j$-th BP:

$A_{C 2 j}=S A_{c c} / S A_{j}$.

In the given example, the following companies are excluded from the analysis: $\mathrm{BP}_{4}$ (weaker than $\mathrm{CC}$ ) and $\mathrm{BP}_{6}$ (just slightly better, practically equal with $\mathrm{CC}$ ). This yields the following:

$A_{C 22}=S A_{c c} / S A_{2}=0.530 / 0.818=0.648$
$A_{C 23}=S A_{c c} / S A_{3}=0.530 / 0.875=0.606$
$A_{C 25}=S A_{c c} / S A_{5}=0.530 / 0.729=0.727$
$A_{c 27}=S A_{c c} / S A_{7}=0.530 / 0.696=0.761$

Before calculating the $\mathrm{TCA}_{\mathrm{j}}$, value it is necessary to determine $\mathrm{w}_{\mathrm{C} 1}$ and $\mathrm{w}_{\mathrm{C} 2}$. In the given example, the managers from the $\mathrm{CC}$ - due to their modest financial potential - opted for the following distribution of relative weights: $\mathrm{w}_{\mathrm{C} 1}=0.4 ; \mathrm{w}_{\mathrm{C} 2}=0.6$. This yields the following: $\mathrm{TCA}_{2}=\mathrm{A}_{\mathrm{C} 12} \cdot \mathrm{W}_{\mathrm{C} 1}+\mathrm{A}_{\mathrm{C} 22} \cdot \mathrm{w}_{\mathrm{C} 2}=0.818 \cdot 0.4+0.648 \cdot 0.6=0.716$ 


\begin{tabular}{|c|c|c|c|c|c|c|}
\hline \multirow{2}{*}{$C C\left(B_{1}\right)$} & \multirow{2}{*}{$\mathrm{BP}_{7}$} & \multirow{2}{*}{$X_{i}\left(w_{i}\right)$} & \multicolumn{4}{|c|}{ Actions $\mathbf{A}_{\mathbf{k}}$} \\
\hline & & & $\mathbf{A}_{1}$ & $A_{2}$ & $\mathbf{A}_{3}$ & $\mathrm{~A}_{4}$ \\
\hline 0.448 & 0.667 & $\mathrm{X}_{1}(0.4500)$ & 0.67 & 0.8 & 0.75 & 0.8 \\
\hline 0.495 & 0.771 & $X_{2}(0.1591)$ & 0.77 & 0.8 & 0.75 & 0.8 \\
\hline 0.657 & 0.633 & $X_{3}(0.1435)$ & 0.63 & 0.66 & 0.75 & 0.8 \\
\hline 0.609 & 0.652 & $\mathrm{X}_{4}(0.1305)$ & 0.65 & 0.61 & 0.75 & 0.8 \\
\hline 0.652 & 0.833 & $X_{5}(0.1169)$ & 0.83 & 0.65 & 0.75 & 0.8 \\
\hline \multicolumn{3}{|c|}{ Aggregate assessments of actions $\mathrm{SAA}_{\mathrm{k}}$} & 0.696 & 0.738 & 0.75 & 0.80 \\
\hline
\end{tabular}

Table 6: Possible actions and their aggregate values

$\mathrm{TCA}_{3}=\mathrm{A}_{\mathrm{C} 13} \cdot \mathrm{W}_{\mathrm{C} 1}+\mathrm{A}_{\mathrm{C} 23} \cdot \mathrm{W}_{\mathrm{C} 2}=0.875 \cdot 0.4+0.606 \cdot 0.6=0.714$

$\mathrm{TCA}_{5}=\mathrm{A}_{\mathrm{C} 15} \cdot \mathrm{W}_{\mathrm{C} 1}+\mathrm{A}_{\mathrm{C} 25} \cdot \mathrm{W}_{\mathrm{C} 2}=0.729 \cdot 0.4+0.727 \cdot 0.6=0.728$

$\mathrm{TCA}_{7}=\mathrm{A}_{\mathrm{C} 17} \cdot \mathrm{W}_{\mathrm{C} 1}+\mathrm{A}_{\mathrm{C} 27} \cdot \mathrm{W}_{\mathrm{C} 2}=0.696 \cdot 0.4+0.761 \cdot 0.6=0.735$

In accordance with the obtained results, the decision was made that the $C C$ in its business activities should aim at achieving the level of $\mathrm{BP}_{7}$. Such a solution may seem very modest. However, if the CC's current aggregate distance in relation to $\mathrm{BP}_{7}(-0.175)$ is observed in Table 4, it would be clear that that the percentage of improvement in relation to the current position would be significant $(0.166 / 0.530 \cdot 100 \approx 31 \%)$. When the CC reaches the position of $\mathrm{BP}_{7}$, then it can perform new analyses and set higher objectives. In this way, targets in steps would be gradually formed as one of the possibilities given in the reference (Walsh, 2000).

\subsection{Selection of the optimal strategic action}

The competent BP has been selected in the above section, along with the level of business for the analyzed parameters. The desired (required and possible) level of business can be achieved in more ways. It is necessary to observe which actions lead to that level. These are all actions which are in their aggregate value close to the competent $\mathrm{BP}$, which is, in this case $\mathrm{BP}_{7}$. Actions are presented through the possible required parameter values, but in such a way that the aggregate value of each action $\left(S A A_{k}\right)$ is close to the aggregate assessment of the competent BP. In such situations there are usually several typical actions (Table 6):

- Complete copying of the competent BP. In Table 6, it is the action $A_{1}$. The $A_{1}$ parameter values are identical to the $\mathrm{BP}_{7}$ parameters.

- Selective improvement of parameters. In Table 6, it is action $A_{2}$. With action $A_{2}$, the level is improved by applying the parameters which are most important (have the highest relative weight), and other parameters are kept at the same level. Generally speaking, this type of action offers a wide range for defining various possibilities. The number of possibilities for defining the actions increases with the increase in the number of parameters.

- Aligning parameter levels to a value which is slightly higher than the competent BP's aggregate assessment. In Table 6 , it is represented by action $A_{3}$. With action $A_{3}$, all the parameters are improved to the 0.75 value, which is slightly better than $\mathrm{SA}\left(\mathrm{BP}_{7}\right)=$ 0.696 .

- Aligning parameter levels to a value which is considerably higher than the competent BP's aggregate assessment. It is represented by action $A_{4}$ on Table 6 . With action $A_{4}$, all the parameters are improved to a 0.8 value, which is considerably better than $\mathrm{SA}\left(\mathrm{BP}_{7}\right)=0.696$. This could in some way be a control action.

When defining possible actions, it is not advisable to reduce certain parameters. Keeping certain parameters at the same level can be adopted as the weakest possibility.

After defining the possible actions, it is necessary to choose the one which will be applied in the concrete case. A multi-criteria approach is proposed here for selecting the optimal action from the set of those available. The number of criteria and their content depends on the type, size, ambitions and the current situation in the CC, as well as on the nature of the analyzed parameters themselves. The managers from the CC define the criteria and their relative weights. For that purpose, expert opinion could be asked for in some typical cases. The following four criteria with their corresponding relative weights were set for the analyzed example:

$C R_{1}$ - Effects of the action

$\mathrm{CR}_{2}$ - Costs (price) of the action (min)

$\mathrm{CR}_{3}$ - Time required to carry out the action (min)

$\mathrm{CR}_{4}$ - Human resources (number, training, motivation) for the action
(0.2). 
Assessment of actions according to all of the criteria was carried out by giving $[0,1]$ assessments. The assessment was made by the managers from CCs because they are the ones who know the capacities of their respective companies for certain actions. The assessment was made by the group decision-making of the three managers from a CC. In general, giving assessments to actions according to the particular criteria $\left(\mathrm{V}_{\mathrm{kp}}\right)$ is made by quantifying the existing (gathered or accessible) data, or by free estimate if such data do not exist. For the analyzed example, the actions were assessed with the assessments according to all of the criteria (Table 7).

As a matter of fact, Table 7 presents the initial table for the majority of the multi-criteria method analyses which are presented in numerous references, for example in Enea and Piazza (2004); Laininen and Hämäläinen (2003); Larichev et al. (2002); Saaty (1980); Triantaphyllou (2000). This paper considers the simple and often used method of multi-criteria analysis (McCrimmon, 1968; Oberstone, 1990). The aggregate effects of each action are calculated by applying the following formula:

$\mathrm{EA}_{\mathrm{k}}=\sum_{\mathrm{p}=1}^{\mathrm{m}} \mathrm{V}_{\mathrm{kp}} \cdot \mathrm{w}_{\mathrm{p}}$,

in which:

$E A_{k}$ - the aggregate effect of the k-th action, in which $k=1,2, \ldots, r$, and $r$ the number of actions,

$V_{k p}$ - the assessment of the k-th action according to the $p$-th criterion, in which $p=1,2, \ldots, m$, and $m$ - the number of the criteria,

$w_{p}$ - the relative weight of the $p$-th criterion.

For example, for the action $A_{1}$, the action effect is:

$E A_{1}=0.6 \cdot 0.3+0.7 \cdot 0.3+0.8 \cdot 0.2+0.6 \cdot 0.2=0.67$

The aggregate effects of every action calculated in this way actually represent the OWA aggregation operators (Yager, 1988). The action having the highest rank is adopted. In the example given, it is the action $A_{3}$.

\begin{tabular}{|c|c|c|c|c|}
\hline \multirow{2}{*}{$\mathrm{CR}_{\mathrm{p}}\left(\mathrm{W}_{\mathrm{p}}\right)$} & \multicolumn{4}{|c|}{ Actions $\mathrm{A}_{\mathrm{k}}$} \\
\cline { 2 - 5 } & $\mathrm{A}_{1}$ & $\mathrm{~A}_{2}$ & $\mathrm{~A}_{3}$ & $\mathrm{~A}_{4}$ \\
\hline $\mathrm{CR}_{1}(0.3)$ & 0.6 & 0.7 & 0.8 & 0.9 \\
\hline $\mathrm{CR}_{2}(0.3)$ & 0.7 & 0.7 & 0.6 & 0.5 \\
\hline $\mathrm{CR}_{3}(0.2)$ & 0.8 & 0.6 & 0.7 & 0.4 \\
\hline $\mathrm{CR}_{4}(0.2)$ & 0.6 & 0.6 & 0.7 & 0.7 \\
\hline Action effects $\mathrm{EA}_{\mathrm{k}}$ & 0.67 & 0.66 & 0.70 & 0.64 \\
\hline Rank & 2 & 3 & 1 & 4 \\
\hline
\end{tabular}

Table 7: Evaluation of the actions according to all the criteria

\subsection{Formation of the portfolio matrix}

A portfolio matrix was formed here modelled on Chen (2005) in order to better perceive the direction of further strategic actions. Portfolio analysis was carried out for each analyzed parameter separately. The relative gap is plotted on the abscissa between the current situation and the desired (required) situation of the parameters observed. The relative weight of the current situation of the observed parameters (Fig. 2) is plotted on the ordinate. The main difference in relation to the reference (Chen, 2005) is that all the values are quantified. Quantification is here performed for the purpose of a more realistic positioning and for the sake of easier reference in the portfolio matrix. The method is presented below.

The abscissa: Quantification of the relative gap between the current situation (CC) and the desired situation (the selected action $A_{3}$ ) of the observed parameters is carried out according to the maximum value of the relative differences of the parameter situation. For the observed example, it is the value of 0.1359 , which can be seen on the function graph presented in Fig. 1a. The assessments of all the relative differences (gaps) of the observed parameters $\mathrm{V}\left(\mathrm{RD}_{\mathrm{i}}\right)$ are the following:

- for the parameter $X_{1}:|0.448-0.75| \cdot 0.4500=0.1359 \Rightarrow V\left(R D_{1}\right)=1$
- for the parameter $X_{2}:|0.495-0.75| \cdot 0.1591=0.0406 \Rightarrow V\left(R D_{2}\right)=0.3$
- for the parameter $X_{3}:|0.657-0.75| \cdot 0.1435=0.0133 \Rightarrow V\left(R D_{3}\right)=0.1$
- for the parameter $X_{4}:|0.609-0.75| \cdot 0.1305=0.0184 \Rightarrow V\left(R D_{4}\right)=0.14$
- for the parameter $X_{5}:|0.652-0.75| \cdot 0.1169=0.0115 \Rightarrow V\left(R D_{5}\right)=0.08$

The ordinate: Quantification of the present situation relative weights (CC) of the observed parameters is carried out according to the maximum value of the selected action $\left(A_{3}\right)$ relative parameter situations. Therefore, what is required is the maximum value of the products of the selected action parameters with their appropriate relative weight. For the observed example, this is the value of 0.3375 (obtained as the product of 0.45 - 0.75), which can be seen on the function graph presented in Fig. 1b. The assessments of the relative present situation of all the observed parameters $\mathrm{V}\left(\mathrm{CCR}_{\mathrm{i}}\right)$ are the following:

- for the parameter $X_{1}: 0.448 \cdot 0.4500=0.2016 \Rightarrow V\left(C C R_{1}\right)=0.6$

- for the parameter $X_{2}: 0.495 \cdot 0.1591=0.0787 \Rightarrow V\left(C C R_{2}\right)=0.23$

- for the parameter $X_{3}: 0.657 \cdot 0.1435=0.0943 \Rightarrow V\left(C C R_{3}\right)=0.28$

- for the parameter $X_{4}: 0.609 \cdot 0.1305=0.0795 \Rightarrow V\left(C C R_{4}\right)=0.24$

- for the parameter $X_{5}: 0.652 \cdot 0.1169=0.0762 \Rightarrow V\left(C C R_{5}\right)=0.23$ 


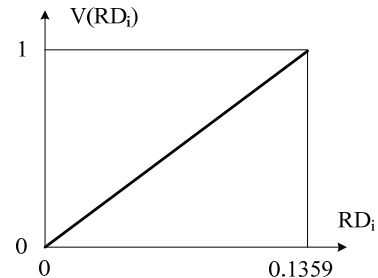

a)

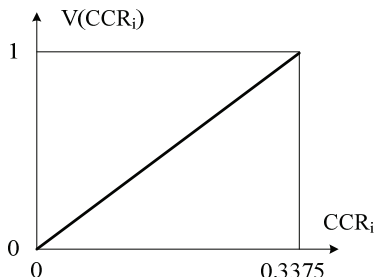

b)

Figure 1: Functions of quantification of the relative gaps and relative values of the present situation

Values quantified in this way are plotted as the coordinates for every parameter in the portfolio matrix (Fig. 2). The coordinates which divide the portfolio matrix into quadrants can be determined as fuzzy assessment average values separately for the abscissa and for the ordinate. In this way, the limit for the abscissa will be:

$(1+0.3+0.1+0.14+0.08): 5=0.324$

and for the ordinate:

$(0.6+0.23+0.28+0.24+0.23): 5=0.316$.

The limit values suggest that the lag behind the desired situation is not considerable, but the relative value of the present situation of the observed parameters is considerably below the average. The positions of all five analyzed parameters in the portfolio matrix are shown in Figure 2. The CC should pay most attention to the parameters $\mathrm{X}_{1}$ i $\mathrm{X}_{2}$, as the weakest and most important at the same time.

A general recommendation for the portfolio matrix set up in this way is that the Catching-up field parameters be directed towards the Narrowing or the Follow-up field, and that the Narrowing and the Follow-up field parameters be directed towards the Anchoring field. Analysis through the portfolio matrix is particularly appropriate in cases where there are a large number of

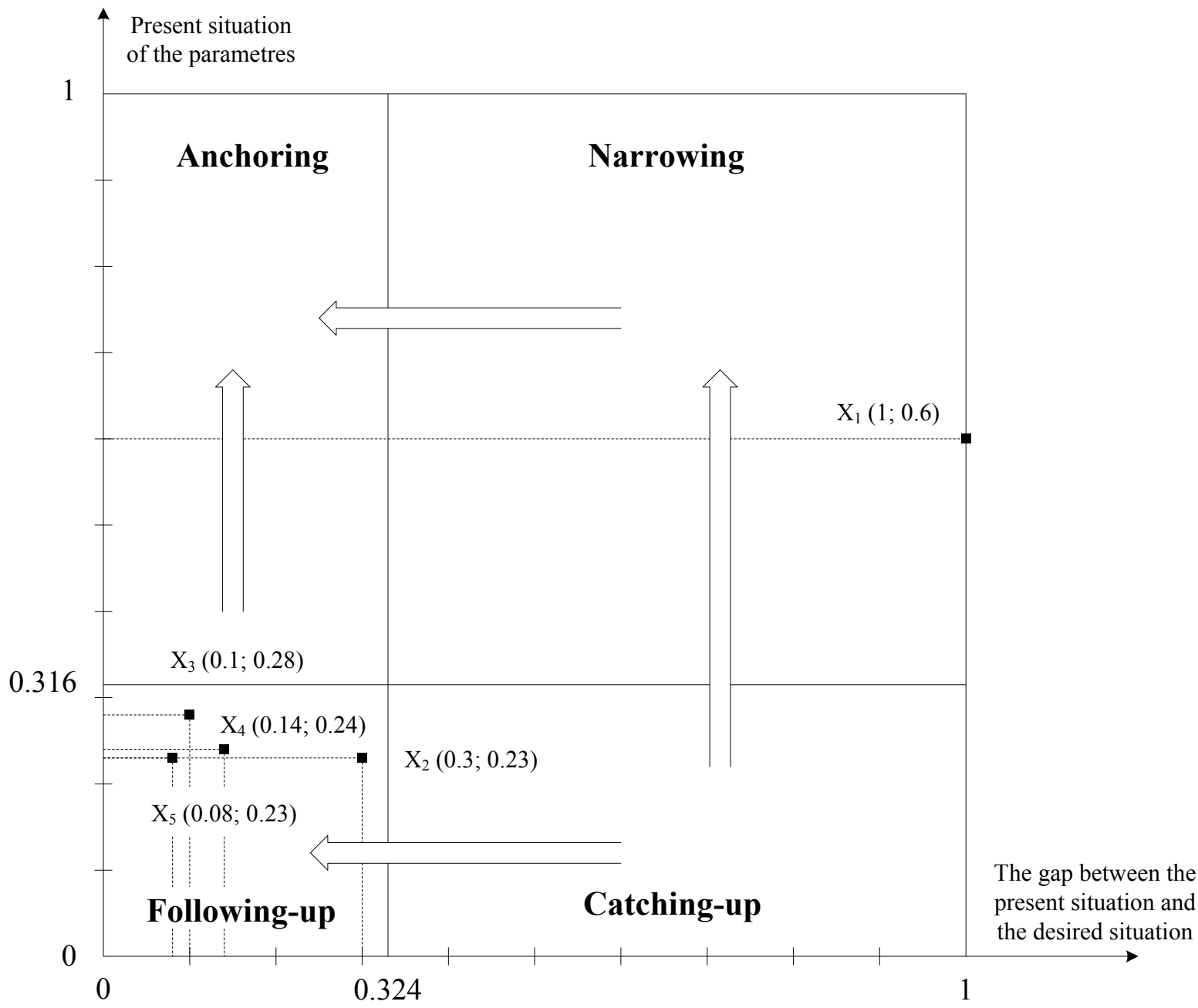

Figure 2: Position of the analysed parameters in the portfolio matrix 
parameters. This enables better observation of the current situation for both individual parameters and groups of parameters.

\section{Conclusion}

The research presented in this paper showed through a concrete example how benchmarking of the PR function can be performed. Seven Serbian companies were ranked according to the five key PR function parameters in Serbian companies. The key parameters were identified by means of factor analysis in research which had been carried out earlier (Study 1). Factor analysis has shown that PR mangers can be promoters of creating a high level of organizational culture in Serbian companies. The identified factors show considerable similarities and they correspond to a great extent with the current situation in the sphere of PR management in other developing countries and countries in transition.

Quantitative methods, which had been presented in another earlier study (Study 2), were used for comparing the companies. The presented quantitative methods can also be used as a mathematical function in benchmarking. The advantages of the proposed procedures could be summarized in the following way:

- All the preliminary parameter values are reduced to the $[0,1]$ interval by quantification. This is very important because of better possibilities for comparison.

- Application of measures for determining the measure of similarity of companies is also made possible. The relative parameter weights are taken into account in the process.

- The potentials of the observed company are also taken into account by the two-criteria selection of the competent benchmarking partner. This is very important for companies which come from weak or underdeveloped economic systems, or, generally speaking, for all those companies whose current position is far from the highest quality business. Such companies would apply benchmarking to the extent to which they are able.

- Defining the possible actions in the form of parameter assessments offers good possibilities for application of different methods of multicriteria analysis in the phase of selecting the optimal action.

- The given procedures are very suitable for quick practical application because of their simplicity. The existence of a database containing the situation and history of the potential benchmarking partners would be of great help, but is not a must.

The studies presented in this paper (Study 3) have correlated earlier research and confirmed the possibility of their practical application. The company labelled as ' $C C^{\prime}\left(B_{1}\right)$, was the subject of deeper analyses. This company was selected because of its considerable lagging behind the leading companies in the field of PR. The obtained results were applied to this company, and the proposed actions carried out. Initial results currently show that the actions which were undertaken have had positive effects on the PR function in the observed company. As a result of this very fact, better overall business results can be expected.

The proposed methods can be analogously applied in other conditions and circumstances (other countries and other companies). The proposed benchmarking methods can also be applied to various other business processes. In other words, the research is not only limited to the PR function. As a matter of fact, similar research in the field of organizational culture are currently being carried out. $[$.

\section{References}

Abbott, J. (2003) "Does employee satisfaction matter? A study to determine whether low employee morale affects customer satisfaction and profits in the B2B sector", Journal of Communication Management, Vol. 7, No. 4, pp. 333-339.

Alshawaf, A.H., Ali, J.M.H., Hasan, M.H. (2005) "A benchmarking framework for information systems management issues in Kuwait", Benchmarking: An International Journal, Vol. 12 No 1, pp. 30-44.

Arceo, A. (2004) "Public relations in Spain: an introduction", Public Relations Review, Vol. 30, Issue 3, pp. 293-302.

Bardhan, N., Sriramesh, K. (2006) "Public Relations in India Review of a Programme of Research", Journal of Creative Communications, Vol. 1, No. 1, pp. 39-60.

Baskin, O., Aronoff, C., Lattimore, D. (2000) Public Relations: the Profession and the Practice, McGraw-Hill, New York.

Black, S. (2003) Public Relations, Clio, Belgrade.

Bouchereau, V., Rowlands, H. (2000) "Methods and techniques to help quality function deployment (QFD)", Benchmarking: An International Journal, Vol. 7 No 1, pp. 8-19.

Brans, J.P., Mareschal, B., Vincke, P. (1984) A New Family of Outranking Methods in Multicriteria Analysis, (Editor: J.P. Brans), Operational Research 1984, North - Holland, Amsterdam.

Brookes R., Little V. (1997) "The New Marketing Paradigma - What does customer focus now mean?", Marketing and Reserch Today, Vol. 25, No. 1, pp. 96-105. 
Camp, R.C. (1989) Benchmarking: The Search for Industry Best Practices that Lead to Superior Performance, W. Company Ltd, Foulsham.

Camp, R.C. (1995) Business Process Benchmarking - Finding and Implementing Best Practices, ASQC Quality Press, Milwaukee, WI.

Chen, H.L. (2005) "A competence - based strategic management model factoring in key success factors and benchmarking", Benchmarking: An International Journal, Vol. 12 No 4, pp. 364-382.

Djordjević, D., Ćoćkalo, D. (2004) Marketing, Technical faculty “Mihajlo Pupin", Zrenjanin.

Djordjević, D., Bešić, C. (2004) Marketing communication, Technical faculty "Mihajlo Pupin", Zrenjanin.

Eid, R., Trueman, M., Ahmed, A.M. (2006) "B2B international internet marketing - a benchmarking exercise", Benchmarking: An International Journal, Vol. 13, No. 1/2, pp. 200-213.

Elliot, G., Koper, E. (2003) "Public relations education from an editor's perspective", Journal of Communication Management, Vol. 7, No. 1, pp. 21-33.

Enea, M., Piazza, T. (2004) "Project Selection by Costrained Fuzzy AHP", Fuzzy Optimization and Decision Making, 3, pp. 39-62.

Farinwata, Sh.S., Filev, D., Langari, R., editors (2000) Fuzzy Control Synthesis and Analysis, John Wiley and Sons, Chichester.

Filipović, V., Kostić, M., Prohaska, S. (2003) Public Relations, Faculty of organizational sciences, Belgrade.

Garg, R.K., Ma, J. (2005) "Benchmarking culture and performance in Chinese organizations", Benchmarking: An International Journal, Vol. 12 No 3, pp. 260-274.

Gill, D.L., Dickinson, S.J., Scharl, A. (2008) “Comminicating sustainability: A web content analysis of North American, Asian and European firms", Journal of Communication Management, Vol. 12, No. 3, pp. 243-262.

Gelders, D., Verckens, J.P., Galetzka, M., Seydel, E. (2007) “Performance communication of the Belgian Railway", Journal of Communication Management, Vol. 11, No. 2, pp. 170-181.

Gunasekaran, A., Patel, C. and Tirtiloglu, E. (2001) "Performance measures and metrics in a supply chain environment", International Journal of Operations and Production Management, Vol. 21, Nos 1/2, pp 71-87.

Guth, D.W. (2000) "The emergence of public relations in the Russian Federation", Public Relations Review, Vol. 26, Issue 2, pp. 191-207.

Höppner, F., Klawonn, F., Kruse, R., Runkler, T. (1999), Fuzzy Cluster Analysis, John Wiley and Sons, New York.

Hwang, C. L., Yoon, K. (1981) Multiple Attribute Decision Making, Methods and Applications, A State-of-the-Art Survey, Lecture Notes in Economics and Mathematical Systems, Springer-Verlag, Berlin.

Kent, M.L., Taylor, M., Turcilo, L. (2006) "Public relations by newly privatized businesses in Bosnia-Herzegovina", Public Relations Review, Vol. 32, No. 1, pp. 10-17.

Kirat, M. (2006) "Public relations in the United Arab Emirates: The emergence of a profession", Public Relations Review, Vol. 32, No. 3, pp. 254-260.
Klement, E.P., Mesiar, R., Pap, E. (2004) “Measure - based aggregation operators", Fuzzy Sets and Systems, Vol. 144, No 1, pp. 3-14.

Koc, E. (2006) "Order three advertisements and get one news story free: Public relations ethics practices of Turkish and international companies in Turkey", Public Relations Review, Vol. 32, No. 4, pp. 331-340.

Koh, S.C.L., Gunasekaran, A., Saad, S.M. (2005) "A business model for uncertainty management", Benchmarking: An International Journal, Vol. 12 No 4, pp. 383-400.

Kotler Ph. (2004) Marketing notional from A to Z, Adižes, Novi Sad.

Kotler, Ph., Armstrong, G. (1996) Principles of Marketing, Prentice Hall International Editions, Englewood Cliffs, New Jersey.

Laininen, P., Hämäläinen, R.P. (2003) "Analyzing AHP-matrices by regresion", European Journal of Operational Research, 148, pp. 514-524.

Larichev, O.I., Kortnev, A.V., Kochin, D.Yu. (2002) "Decision support system for classification of a finite set of multicriteria alternatives", Decision Support System, 33, pp. 13-21.

Lau, H.C.W., Lee, W.B., Lau, P.K.H. (2001) "Development of an intelligent decision support system for benchmarking assessment of business partners", Benchmarking: An International Journal, Vol. 8 No 5, pp. 376-395.

Leonard, A., Grobler, A.F. (2006) "Exploring challenges to transformational leadership communication about employment equity: Managing organizational change in South Africa", Journal of Communication Management, Vol. 10, No. 4, pp. 390-406.

Leskinen, P. (2000) "Measurement, scales and scale independence in the analytic hierarchy process", Journal of Multi-Criteria Decision Analysis, Vol. 9 No 4, pp. 163-174.

Lubbers, Ch.A. (2002) "Using alternative teaching techniques to enhance student performance in the traditional introductory public relations course", Public Relations Review, Vol. 28, Issue 2, pp. 157-166.

McCrimmon, K.R. (1968) "Decision Making Among Multiple-Attribute Alternatives: Survey and Consolidated Approach", RAND Memorandum, RM - 4823 - ARPA.

McNair, J. and Leibfried, K.H.J. (1992) Benchmarking: A Tool for Continuous Improvement, Harper Business Press, New York, NY.

Moffet, S., Anderson-Gillespie, K., McAdam, R. (2008) "Benchmarking and performance measurement: a statistical analysis", Benchmarking: An International Journal, Vol. 15, No. 4, pp. 368-381.

Murray, L. (2003) "Public relations and communication management: Suitable cubjects for management education?", Journal of Communication Management, Vol. 7, No. 1, pp. 9-13.

Neely, A.D. (1998) Measuring Business Performance: Why, What and How, Economist Books, London.

Niemann-Struweg, I., Meintjes, C. (2008) "The professionalism debate in South African public relations", Public Relations Review, Vol. 34, No. 3, pp. 224-229.

Nikolić, M., Djordjević, D., Ćoćkalo, D. (2007) "Research on certain aspects of PR function in Serbian companies", Journal for East European Management Studies, Vol. 12, No. 2, pp. 152-173. 
Nikolić, M., Nikolić, B., Vukonjanski, J. (2007) "Quantitative approach in Benchmarking: Support to Selection of Optimal Strategic Actions", Russian Management Journal, Vol. 5, No. 2, pp. 29-44.

Noghin, V.D. (1997) "Relative importance of criteria: a quantitative approach", Journal of Multi-Criteria Decision Analysis, Vol. 6 No 6, pp. 355363.

Oberstone, J. (1990) Management Science - Concepts, Insights and Applications, West Publ. Co., St.Paul.

Pedrycz, W., Gomide, F. (1998) An Introduction to Fuzzy Sets - Analysis and Design, A Bradford Book, Cambridge and Massachusetts Institute of Technology.

Podinovski, V.V. (2002) "The quantitative importance of criteria for MCDA", Journal of Multi-Criteria Decision Analysis, Vol. 11 No 1, pp. 1-15.

Raupp, J., Ruler, B. (2006) "Trends in public relations and communication management research: A comparison between Germany and The Netherlands", Journal of Communication Management, Vol. 10, No. 1, pp. 18-26.

Rawel, A. (2003) "How far do professional associations influence the direction of public relations education?", Journal of Communication Management, Vol. 7, No. 1, pp. 71-78.

Razmi, J., Zairi, M., Jarrar, Y.F. (2000) "The application of graphical techniques in evaluating benchmarking partners", Benchmarking: An International Journal, Vol. 7 No 4, pp. 304-314.

Ribeiro, L.M.M., Cabral, J.A.S. (2006) "A benchmarking methodology for the metalcasting industry", Benchmarking: An International Journal, Vol. 13, No. 1/2, pp. 23-35.

Royo, A.S., Verdegay, J.L. (2000) "Coherence Measures on Finite Fuzzy sets", International Journal of Uncertainly, Fuzziness and Knowledge Based Systems, Vol. 8 No. 6, pp. 641-663.

Saaty, T.L. (1980), The Analytic Hierarchy Process, McGraw-Hill, New York.

Sajfert Z., Djordjević D., Bešić C. (2006) Management trends, Technical faculty "Mihajlo Pupin", Zrenjanin.

Srinivasan, V., Shoker, A. D. (1973) "Linear Programming Techniques for Multidimensional Analysis of Preference", Psychometrica, Vol. 25, No 1, pp.: 337-369.

Sterne, G.D. (2008) "Business perception of public relations in New Zealand", Journal of Communication Management, Vol. 12, No. 1, pp. 3050 .

Taylor, M. (2004) "Exploring public relations in Croatia through relational communication and media richness theories", Public Relations Review, Vol. 30, Issue 2, pp. 145-160.

Triantaphyllou, E. (2000) Multi-Criteria Decision Making Methods: A Comparative Study, Kluwer Academic Publishers, Boston.

Ungan, M. (2004) "Factors affecting the adoption of manufacturing best practices", Benchmarking: An International Journal, Vol. 11 No 5, pp. 504-520.

Venetucci, R. (1992) "Benchmarking: a reality check for strategy and performance objectives", Production and Inventory Management Journal, Vol. 33, No. 4, pp 32-36.
Walsh, P. (2000) "Targets and how to assess performance against them", Benchmarking: An International Journal, Vol. 7 No 3, pp. 183-199.

Wolf, K. (2006) "PR cereer progression? The gap between traditional research and the UK industry's perception", Journal of Communication Management, Vol. 10, No. 2, pp. 174-190.

\section{Wragg, D. (1996) Media Relations, Clio, Belgrade.}

Yager, R.R. (1988) "On ordered weighted averaging aggregation operators in multi/criteria decision making", IEEE transactions on systems, man and cybernetics, Vol. 18, pp. 183-190.

Zairi, M. (1998) "Benchmarking at shorts", International Journal of Benchmarking for Quality Management and Technology, Vol. 5, No. 1, pp 13-20.

Žlof, K. (2007) “ The journalists' idea concerning the influence of PR professionals on public opinion ", Medianali, Vol. 1, No. 2, pp. 33-46. (in Croatian) 